\title{
Experimental measurement of dynamic concentration of nanofluid in laminar flow
}

\author{
Jiaju Hong ${ }^{1,2}$, Sheng Liu ${ }^{1,3}$, Yuying Yan ${ }^{1,5^{*}}$, Paul Glover ${ }^{4}$ \\ ${ }^{1}$ Fluids \& Thermal Engineering Research Group, Faculty of Engineering, University of Nottingham, UK \\ ${ }^{2}$ Marine Engineering College, Dalian Maritime University, Dalian, China \\ ${ }^{3}$ College of Mechanical and Electrical Engineering, Hohai University, Changzhou, China \\ ${ }^{4}$ School of Astronomy, University of Nottingham, Nottingham, UK \\ ${ }^{5}$ Centre for Fluids \& Thermal Engineering, University of Nottingham Ningbo, China \\ *Corresponding author: yuying.yan@nottingham.ac.uk
}

\begin{abstract}
Nanofluid is thought to have a potential enhancement in heat transfer behaviour of fluid. The nanoparticle concentration in nanofluid is one of the most important factors that affect the nanofluid behaviour. The static concentration was applied in the researches under flowing condition. In this paper, Nuclear Magnetic Resonance (NMR) scanning was applied to study the dynamic concentration of nanofluid flow in pipe. The experiments were carried out with ferrofluid under different concentration and temperature. A new parameter $T_{2}{ }^{*}$ was introduced in the study. Experiments were carried out to obtain the $T_{2}{ }^{*}$ of nanofluid in the pipe. An empirical equation based on $T_{2}{ }^{*}$ and temperature was proposed to calculate the concentration of nanoparticles. Then, experiments were carried out with flowing ferrofluid in pipe. The dynamic concentration was calculated with the empirical equation. It has a highest concentration near the pipe wall. The concentration decreases from the wall to the pipe centre. Furthermore, the experiment result also gives out a chance to investigate the mechanism of nanoparticle movement in laminar flow with the concentration gradient along radius.
\end{abstract}

Keywords: dynamic concentration, nanofluid, NMR

\section{Nomenclature}

$\begin{array}{llll}\mathrm{M} & \text { nuclear spin magnetization }(\mathrm{A} / \mathrm{m}) & \mathrm{t} & \text { time }(\mathrm{ms}) \\ \mathrm{T} & \text { temperature }\left({ }^{\circ} \mathrm{C}\right) & \mathrm{S} & \text { non-dimensional Signal Strength }\end{array}$


$\mathrm{T}_{1} \quad$ longitudinal relaxation time

V flow velocity $(\mathrm{mm} / \mathrm{s})$

$\Delta \mathrm{B}_{0} \quad$ local varying field strength difference

\section{Greek letters}

$\phi \quad$ volume concentration (\%)

$\lambda$ thermal conductivity $(\mathrm{W} /(\mathrm{m} \cdot \mathrm{K}))$

\section{Subscripts}

xy surface formed by $\mathrm{x}$ and $\mathrm{y}$ axis

ef effective thermal conductivity

f fluid
$\mathrm{T}_{2}$ transverse relaxation time

$\mathrm{k} \quad$ slope of decaying line 
The uneven dynamic concentration will affect the behaviours of nanofluids especially heat transfer. The concentration of nanofluid is always assumed as equal in these researches for the lack of measurement methods, which is measure in static state and observed from machines such as Transmission Electron Microscopy (TEM) before the experiment.[13-16] However, the heat transfer behavior is closely related to the specific heat and conductivity of nanofluid, which is decided by the nanoparticle concentration of nanofluid. The conductivity always has optimized concentration where conductivities reach maximum, while the specific heat considered always going down as concentration increases.[12]

Even though the heat transfer performance of nanofluid can be treated as a whole, it may still be possible that circumstances may be different and affect the gradient and cause different performance under the same concentration, which makes the real concentration in dynamic very different from the one observed in static using TEM. And also the heat transfer efficiency of nanofluid is decided by the conductivity of nanofluid near the boundary surface. So, the concentration of nanofluids cannot be assumed as equal under flowing condition.

Therefore, the dynamic concentration of cross section along the flow channel is necessary for analysing the performance of nanofluid. A new method for dynamic concentration measurement, Nuclear Magnetic Resonance (NMR), is introduced to measure the dynamic concentration distribution of cross section of flow channel. A new overall parameter from NMR, which is easily detected and has a unique relation with concentration, temperature and velocity etc., is firstly introduced in the measurement of dynamic nanoparticle concentration with NMR in this work. Then a method to calculate the dynamic concentration distribution of cross section with this parameter is developed. The experiments are carried out with ferrofluid (a magnetic nanofluid using $\left.\mathrm{Fe}_{3} \mathrm{O}_{4}\right)$ in the pipe under different concentration and temperature. The dynamic concentration of nanoparticles is calculated with the method developed in this paper. The thermal conductivity of ferrofluid flowing in the pipe is also studied with the dynamic concentration obtained with the method in this paper. 


\section{NMR Theory}

NMR is a powerful and theoretically complex analytical tool. It was first described and measured in molecular beams by Isidor Rabi in 1938, later Felix Bloch and Edward Mills Purcell expanded the technique for use on liquids and solids in 1946. NMR is developing as one of the most important method in medical research.[19, 20] The NMR method has also been applied to study water migration in plant.[35]

NMR performances experiment on the nuclei of atoms, not the electrons. Longitudinal (or spin-lattice) relaxation time $T_{1}$ and transverse (or spin-spin) relaxation time $T_{2}$ are the two basic parameters in NMR. $T_{1}$ is the decay constant for the recovery of the $\mathrm{z}$ component of the nuclear spin magnetization towards its thermal equilibrium value, and $T_{2}$ is the decay constant for the component of perpendicular magnetization field.[21] $T_{2}$ is the key relaxation time in this paper. In nanofluid, the nuclei, mainly hydrogen atom in water, would release signals during its magnetization process, which would decay away when it goes back to equilibrium distribution, as is shown in Fig. 1. So $T_{1}$ and $T_{2}$ become the most important relaxation times in the progress with different tissues or fluid situations. In general,

$$
\begin{aligned}
& M_{z}(t)=M_{z, e q}-\left[M_{z, e q}-M_{z}(0)\right] e^{-t / T_{1}} \\
& M_{x y}=M_{x y}(0) e^{-t / T_{2}}
\end{aligned}
$$

Where, $\mathrm{M}$ is affected by external magnetic field.

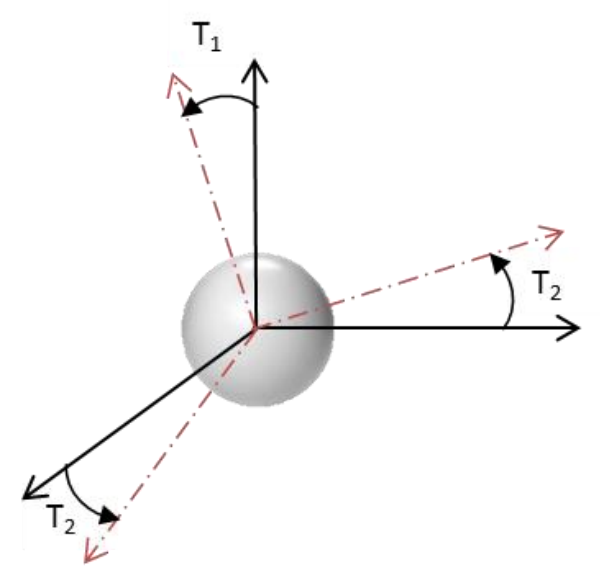

Fig. 1: Relaxation time of resonance signals from nuclei

So when the nuclei are going back to equilibrium, the signals it releases will be detected by NMR machine, recorded as the signal intensity $S$. By taking logarithm of 
the $T_{2}$ signals intensity $S$ in Eq. 2, the equation is as below,

$$
\log (S)=-t / T_{2}+\log (M)
$$

The slope is,

$$
k=-1 / T_{2}
$$

The $\log (S)$ has a linear relation with time $t$ in Eq. (3), for $T_{2}$ is a decay constant related to the fluid characteristics. So the $T_{2}$ performs much better than $T_{1}$ based on this point. In real case, the distribution of resonance frequency can lead to a loss of signal intensity, which causes the signals decaying faster than theory, then a smaller $T_{2}$ is measured, which is $T_{2}{ }^{*}$,

$$
\frac{1}{T_{2}^{*}}=\frac{1}{T_{2}}+\frac{1}{T_{i n \mathrm{hom}}}=\frac{1}{T_{2}}+\gamma \Delta B_{0}
$$

Then $T_{2}{ }^{*}$ is used to instead $T_{2}$ in the following discussion. So the concentration $\phi$ measured by NMR are related to $T_{2}{ }^{*}, T$ and $v$,

$$
f\left(\phi, T_{2}^{*}, T, v\right)=0
$$

where, $\phi$ is concentration, meaning $\phi=0.1$ refers when $0.1 \%$ volume for example.

It is hard to analyse the effects induced by velocity on dynamic concentration directly from the data provided by NMR. At the same time, $T_{2}{ }^{*}$ is seriously affected by velocity, the effect of velocity is considered when analysing $T_{2}{ }^{*}$ from the signal, and Eq. 6 can then be written as,

$$
\phi=g\left(T_{2}^{*}, T\right)
$$

\section{Experimental}

In NMR medical scanning there is always something called contrast agent, which can reduce the relaxation time, so that the scanning can be done as fast as possible when doing research, especially on patients. Most researchers would use solutions with metal ions to achieve that goal. In which $\mathrm{Mn}^{2+}, \mathrm{Cu}^{2+}$ and $\mathrm{Fe}^{2+}, \mathrm{Fe}^{3+}$ are the most widely used metal ions.[22] It already has been proved by some researchers that in nanofluid, such as $\mathrm{Fe}_{3} \mathrm{O}_{4}$ can still give a very good performance as a $T_{2}$ contrast agent, which means 
that it could strongly affect the $T_{2} \cdot[23,24]$ Since $\mathrm{Fe}_{3} \mathrm{O}_{4}$ can affect $T_{2}$, the $T_{2}$ is very suitable for the overall parameter discussed above. So ferrofluid is chosen as the working substance in the experiments.

The ferrofluid used in the experiments is composed of pure water as carried fluid, $\mathrm{Fe}_{3} \mathrm{O}_{4}$ as nanoparticles and oleic acid as its surfactant. The $\mathrm{Fe}_{3} \mathrm{O}_{4}$ nanoparticles are dispersed in Sodium Dodecyl Sulphate (SDS), with the final size within the range of 9$10 \mathrm{~nm}$ and hydraulic diameter of $12 \mathrm{~nm}$.

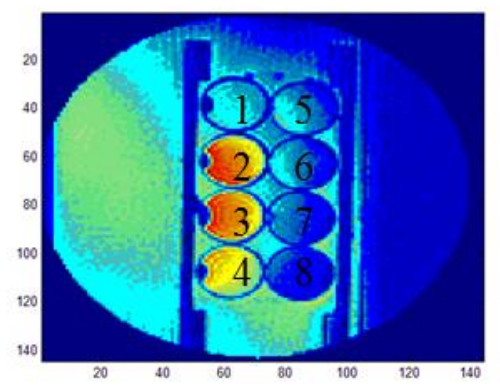

Fig. 2a: Static Experiment

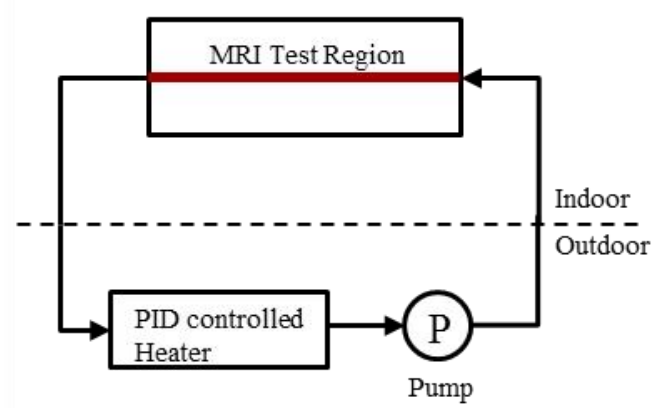

Fig. 2b: Dynamic Experiment

Fig.2: Static and Dynamic Experiment

The experiments were carried out in three parts. First, the $T_{2}{ }^{*}$ was measured in static measurement at different temperature and nanofluid volume concentration. The ferrofluid was in the tube with a diameter of $18 \mathrm{~mm}$, and scanning was carried out on certain section of tube. Eight test tubes were tied between two boards and put into the scanning, with water bath around to heat them up from $20^{\circ} \mathrm{C}$ to $69^{\circ} \mathrm{C}$ with PID controller, as can be seen in Fig. 2a. The fluids measured in static experiments include pure water, SDS water solution at four times the Critical Micelle Concentration (CMC) with volume percentage of $0.01 \%, 0.03 \%, 0.05 \%, 0.07 \%, 0.09 \%, 0.1 \%, 0.11 \%, 0.2 \%$, $0.3 \%, 0.4 \%$ and $0.5 \%$. The nanofluid used in the experiment comes from a previously prepared base fluid in the lab, and could be stable for around two years. The experiments were carried out with these 7 concentrations at 10 different temperatures from $20^{\circ} \mathrm{C}$ to $69^{\circ} \mathrm{C}$.

Second, the results from static experiments were analysed to obtain the nanofluid concentration. The resolution of NMR in our experiment is around $1 \mathrm{~mm}$, which means 
there are several $T_{2}{ }^{*}$ Signals at the section of tube. By taking average value of each $T_{2}{ }^{*}$, the overall $T_{2}{ }^{*}$ of every concentration were calculated at different temperatures. All the data including $T_{2}{ }^{*}$, temperature and concentration from these 70 tests were put into empirical Eq.6 to obtain the parameters. The equation will be later used to analyse the concentration gradient in dynamic flow scanning.

Then the dynamic concentration measurements were carried out with ferrofluid with a volume concentration of $0.05 \%$ in tank. The ferrofluid was pumped into the NMR machine through a 5-metre pipe from the tank, and then flowed back to the tank, the temperature is controlled with PID controller, as can be seen in Fig. 2b. The red line indicates the part of the pipe going through the NMR machine horizontally and being scanned. When temperature reached at some certain points, the scans were carried out with flowing ferrofluid and the state immediately after the pump shut off, respectively. The time interval is 10 minutes. The profile of the flow was scanned to achieve a group of $T_{2}{ }^{*}$ (each pixel has a $T_{2}{ }^{*}$ ) data in flow and stable condition. And the concentration at each pixel of the dynamic concentration scanning will be calculated separately using the empirical equation obtained from section 2.

\section{Empirical equation of NMR concentration measurement}

The experiments were carried out with Philip 3T Achieva NMR machine, with 3 Tesla magnetic field and $128 \mathrm{MHz}$ Radio Frequency. The data from NMR scanning are a 3D database with huge numbers of signal values. These data were analysed and calculated into the decaying line. Then the decaying trend of signal intensity, the slope $k$, was used for further calculation.

Fig.3 gives out the trend of $T_{1}$ signals and $T_{2}$ signals during a scanning process. The $T_{1}$ signal gets weaker and weaker at first, and then goes up after $600 \mathrm{~ms}$, this is because negative value cannot be plot under NMR data, and is shown in positive value. While the $T_{2}$ signal just gets weaker during the scanning. The two lines perfectly match with NMR theory. 


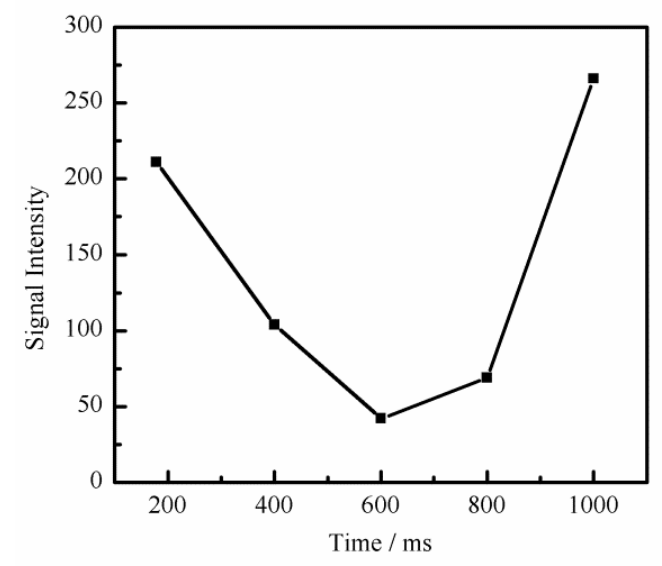

Fig.3a decaying trend of $T_{1}$ signals

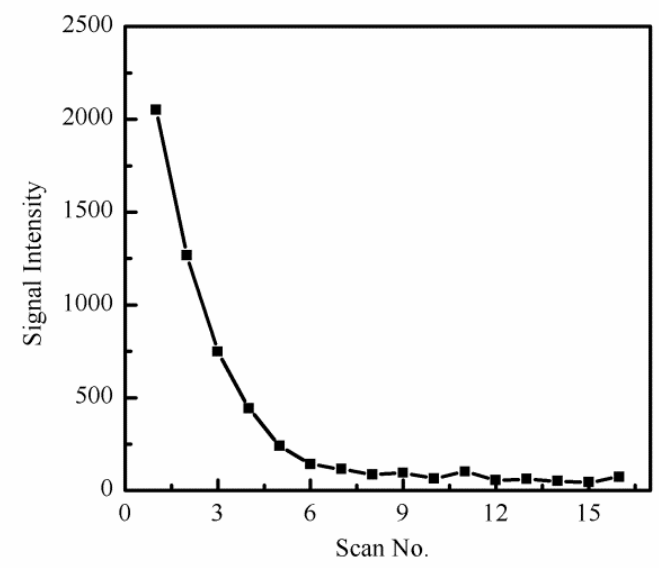

Fig. $3 b$ decaying trend of $T_{2}$ signals

Fig. 3 The decaying trend in NMR $(0.01 \%$ volume $)$

The slopes of curve of logarithm $S$ against time were calculated for the 70 experiments, which equals to $1 / T_{2}{ }^{*}$, in Eq. 3. Fig. 4a gives out the three typical curves of the $\ln (S)$ against time of $0.01 \%$ volume concentration, and Fig. $4 \mathrm{~b}$ gives out the three typical curves of $0.1 \%$ volume concentration.

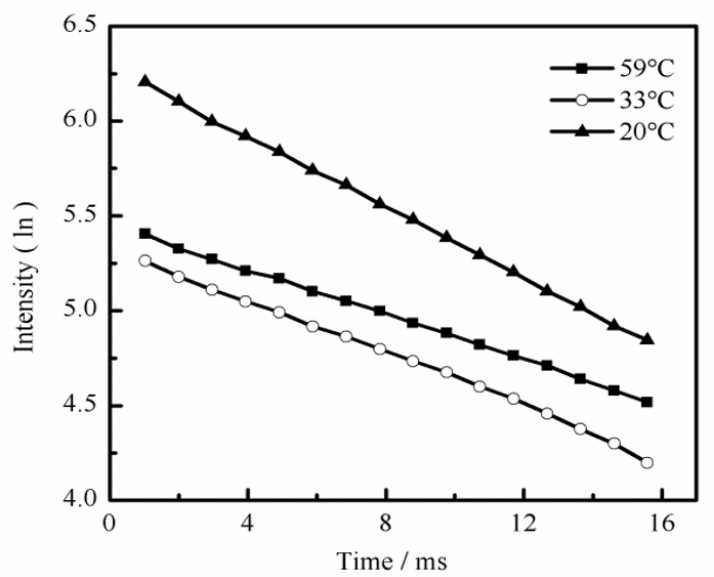

Fig.4a $0.01 \%$ concentration

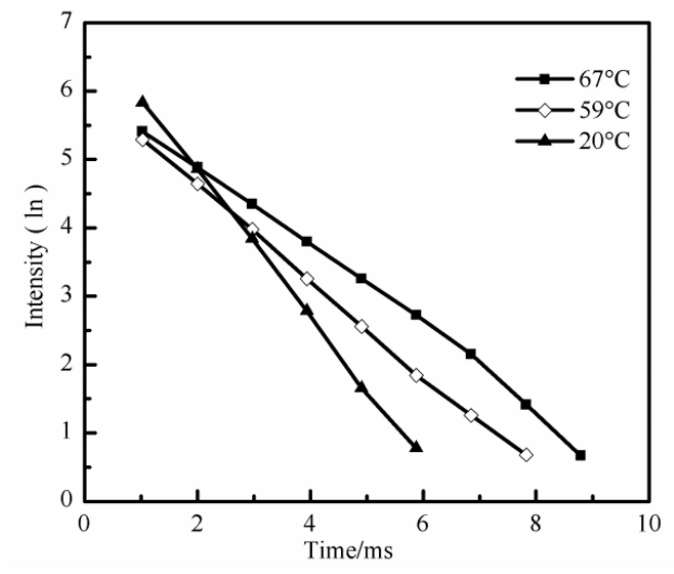

Fig. $4 \mathrm{~b} 0.1 \%$ concentration

Fig. 4 The relationship between logarithm intensity and time

The curve of $20^{\circ} \mathrm{C}$ is on the top, the $59^{\circ} \mathrm{C}$ is in the middle, and the $33^{\circ} \mathrm{C}$ is at the bottom for $0.01 \%$ concentration, as can be seen in Fig. $4 \mathrm{a}$. While the curve of $20^{\circ} \mathrm{C}$ is at the bottom, the $33^{\circ} \mathrm{C}$ is in the middle, and the $59^{\circ} \mathrm{C}$ is on the top for $0.1 \%$ concentration, as can be seen in Fig.4b. The lowest temperature curve decays faster, while the highest temperature decays relatively slow. The slope $k$ decreases when temperature rises for each concentration. These curves show almost linear relation between $\ln (S)$ and temperature, so this concentration measurement method can be 
proved to be acceptable and accurate.

The slope $k$ the 70 experiments were calculated, as can be seen in Fig.5. It can be found out that the signal of pure water does decay very slowly for pure water, which means a very high $T_{2}$. So the slope $k$ is very small which is very close to 0 and decay very slowly. The differences of the slopes $k$ at different temperatures are very small for pure water.

It has been observed that the ferrofluid with $0.01 \%$ volume concentration looks like as transparent as pure water, while the ferrofluid with $1 \%$ volume concentration is pretty dark. The slopes $k$ of low concentration ferrofluid are small and decay slowly, as can be seen in Fig.5. As the concentration increase, the decaying speed of slope $k$ increases. The slope line of $0.3 \%$ concentration is no longer linear, because the nanoparticles in ferrofluid affect the signals when the concentration is high. The NMR scanning cannot be carried out with high concentration ferrofluid.

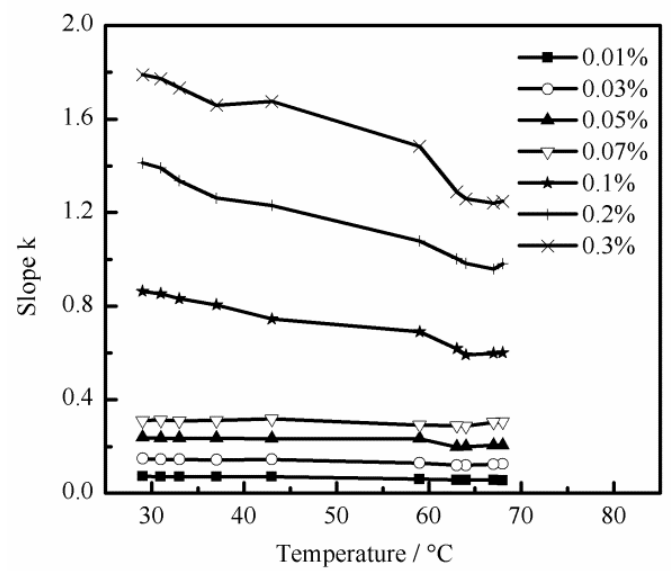

Fig. 5: Slope $k$ against Temperature under different concentration

The signals obtained from NMR scanning are $T_{2}{ }^{*}$, but the $T_{2}{ }^{*}$ equals to $-1 / k$, according Eq. 4. So, $T_{2}{ }^{*}$ is used to instead the $k$ in Fig.5, then the curves of $T_{2}{ }^{*}$ against concentration were plotted in Fig. 6. The $T_{2}{ }^{*}$ increases with the decrease of concentration under certain temperature. It can be found out that temperature, $T_{2}{ }^{*}$ and concentration have a clear relationship. So, with temperature and $T_{2}{ }^{*}$ measured by NMR, the concentration can be easily obtained.

In the experiment condition, the linear region of $T_{2}{ }^{*}$ with concentration is only 
within the range below $0.1 \%$ volume, as can be seen in Fig. 6 . Because when the concentration is higher than $0.1 \%$, the $T_{2}{ }^{*}$ signals will be affected by the $\mathrm{Fe}_{3} \mathrm{O}_{4}$ nanoparticles in ferrofluid. But some researches show that $T_{2}$ is actually going down linearly with logarithm of concentration when using metal ion solutions.

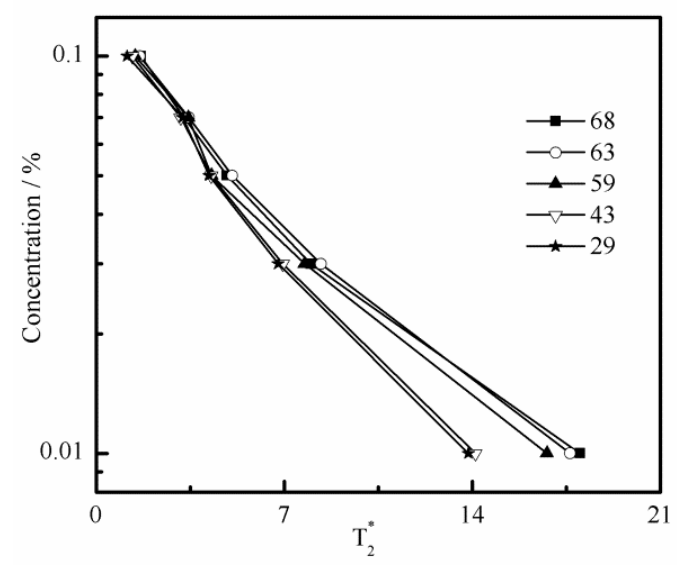

Fig. 6: Concentration against $T_{2}{ }^{*}$ under different temperature

Then the empirical equation was solved with $T_{2}{ }^{*}$, temperature and concentration based on Eq.7,

$$
\begin{aligned}
& \phi=e^{\left(A-T_{2}^{*}\right) / B}-C \\
& A=-7.38-0.028 * T \\
& B=3.63+0.014 * T \\
& C=-0.0043-0.000048 * T
\end{aligned}
$$

The standard error of Eq. 8 is 0.0046 , and the relative error is $8.25 \%$ in average. The result from experiment and Eq. 8 were compared at the range of $T_{2}{ }^{*}$ ranging from 0 to 20 , volume concentration from $0.01 \%$ to $0.1 \%$ and temperature from $28^{\circ} \mathrm{C}$ to $70^{\circ} \mathrm{C}$, as can be seen in Fig. 7. It can be seen that the difference between experiment and the result from Eq. 8 is very small. The Eq. 8 has a high accuracy. 


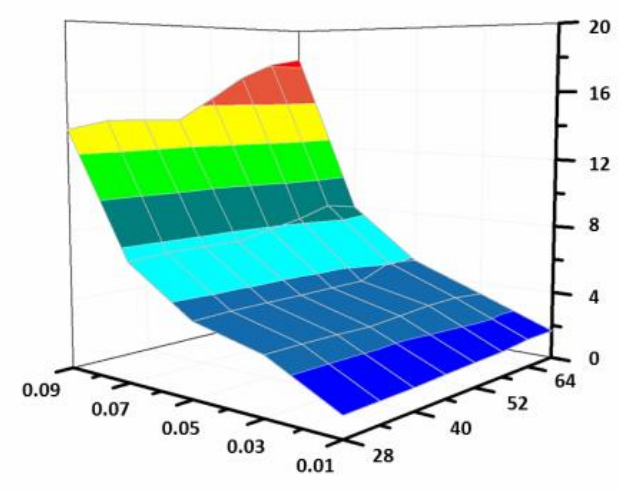

Fig. 7a Experiment

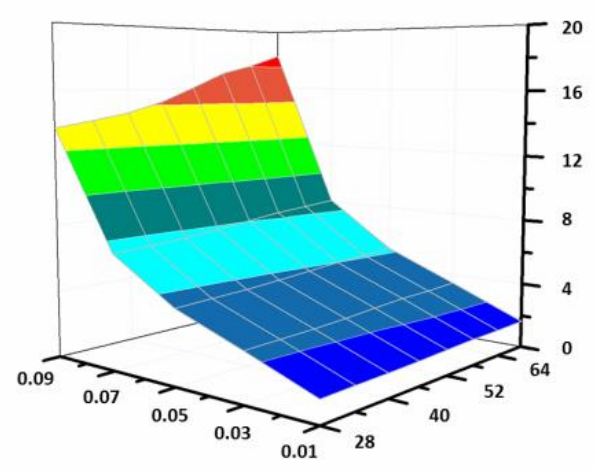

Fig. 7b Equation

Fig. 7 Contour of $T_{2}{ }^{*}$ distribution in experiment and equation with bottom axis concentration and temperature

\section{Dynamic Concentration and Heat Transfer}

The two curves in Fig. 8 are the relationship between logarithm intensity and time of under flow and static condition in the pipe. It can be found out that the signals of flow condition decay faster than static condition. Because the signals obtained by the NMR scanning are from the certain atoms in the fluid, those atoms will move away with the fluid. The decay speeds of initial part of these two curves are almost the same, for the velocity of the fluid is very small in the experiment condition. The signal loss caused by velocity is below the sensitivity of signal receiver. As the scanning carried on, the signal sources move away as well, and cause a loss in signal. And the curve decay speed faster with the increase of flow velocity. So the effects of velocity on concentration can be included in $T_{2}{ }^{*}$.

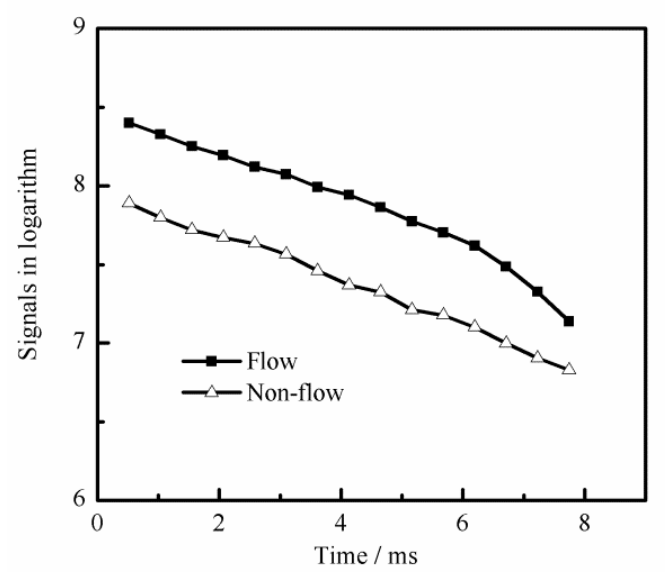

Fig. 8 The relationship between logarithm intensity and time of under low and static 
condition

The $0.05 \%$ volume concentration ferrofluid is adopted in dynamic scanning. The ferrofluid is circled around in the pipe using a pump, during the scanning. The flow in the pipe is laminar flow during experiment, at a maximum $25 \mathrm{~mm} / \mathrm{s}$ velocity at centre line. The diameter of the tube used in the experiments is about 8 pixels, and the cross section is divided into 72 pixels ( $8 \times 9$ pixels), as can be seen in Fig. 9. Each pixel gives a group of individual $T_{2}{ }^{*}$ signals, which means there are 72 groups of $T_{2}{ }^{*}$ signals. The 72 groups of $T_{2}{ }^{*}$ signals are seriously analysed, and then put into Eq. 8 with temperature to calculate the concentration of each pixel, separately. Then the dynamic concentration distribution of the cross section is obtained with the concentrations of 72 pixels, as can be seen in Fig.9b.

It is clear that the dynamic concentration distribution of the cross section under flow condition is closely related to the velocity distribution of the cross section. The highest concentration appears near the wall of the tube, which is about $0.06 \%$ volume, and the concentration at the centre of the cross section is about $0.03 \%$ volume. The concentration decreases from wall to the centre of tube along the radius, as can be seen in Fig. 10. This is because nanoparticles have a strong tendency of gathering near the interface or wall, under the effects of surface tension and wall adherence. At the same time, the velocity near the wall is relatively small compare to the centre and the flow is stable under laminar flow condition, which may also contribute to the aggregation of nanoparticles near the wall. So as long as the flow state is laminar flow in pipe, the cross section of pipe will have almost the same concentration distribution like Fig. 9b and Fig. 10. 


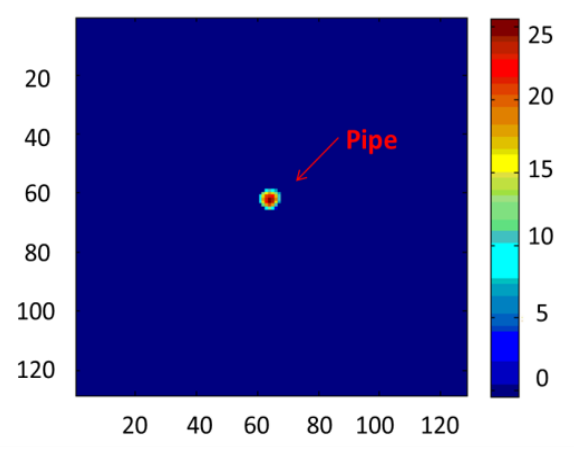

Fig. 9a: Velocity Distribution $(\mathrm{mm} / \mathrm{s})$

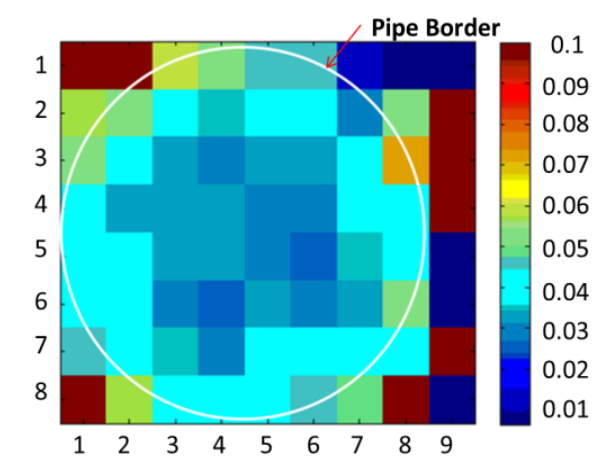

Fig. 9b: Concentration Distribution

Fig. 9: Concentration and velocity distribution across the tube

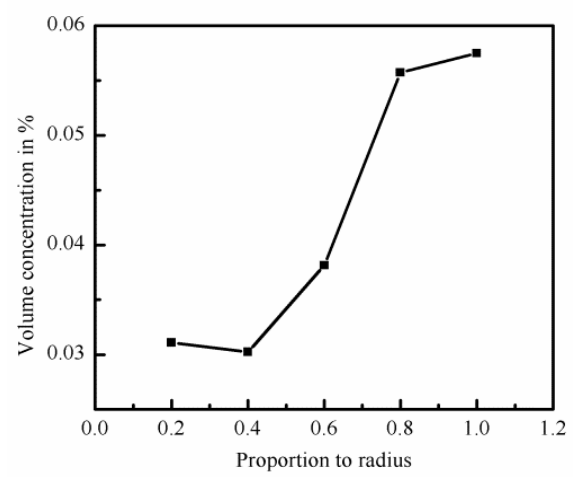

Fig. 10 The concentration gradient along the radius

The average concentration of the cross section measured in the experiment is $0.046 \%$ calculated with Eq. 8 , which is about $0.004 \%$ less than the CMC concentration in the tank. This is because the distribution of nanoparticles isn't uniform in the tank. And the pump induces a serious turbulence around the pump, which also affect the nanoparticle concentration in the tank. Then the concentration of the nanofluid that pumped into the tube may have a small difference with the CMC concentration in tank. So the dynamic concentration measured by NMR with Eq. 8 is acceptable.

The heat transfer behavior of nanofluid in the pipe is closely related to the thermal conductivity of the nanofluid. The conductivity near the wall is the main factor that decides the convective heat transfer speed between the wall and water in tube. For the non-uniform concentration distribution, the thermal conductivity in the tube isn't uniform. One of the most conmen used thermal conductivity calculating method for nanofluid is, 


$$
\lambda_{e f}=\phi \cdot \lambda_{p}+(1-\phi) \cdot \lambda_{f}
$$

The thermal conductivity of $\mathrm{Fe}_{3} \mathrm{O}_{4}$ nanoparticles is considered the same as that of $\mathrm{Fe}_{3} \mathrm{O}_{4}$ powders, which is $6 \mathrm{~W} /(\mathrm{m} \cdot \mathrm{K})$, and water $0.55 \mathrm{~W} /(\mathrm{m} \cdot \mathrm{K}) \cdot[27]$ Thermal conductivity of the nanofluid with average concentration in tube is $0.5525 \mathrm{~W} /(\mathrm{m} \cdot \mathrm{K})$, $0.5529 \mathrm{~W} /(\mathrm{m} \cdot \mathrm{K})$ with dynamic concentration, and $0.5532 \mathrm{~W} /(\mathrm{m} \cdot \mathrm{K})$ near the wall. The difference of dynamic conductivity and conductivity near wall with the effective conductivity will increase when the concentration increases. The conductivity near the wall will be around $5 \%$ higher than the average conductivity at $1 \%$ concentration with equation (8).

\section{Conclusion and Future Perspective}

In this paper, a new method to measure the dynamic concentration of nanofluid flow in pipe with NMR is proposed. A new parameter $T_{2}{ }^{*}$ is proposed in this paper. $T_{2}{ }^{*}$ is a relaxation time commonly used in NMR researches, which indicates the decay constant for the component of perpendicular magnetization field. The concentration is closely relating to $T_{2}{ }^{*}$, velocity and temperature. And the effects of velocity on dynamic concentration are considered in $T_{2}{ }^{*}$ in this work.

70 experiments were carried out with different temperature and concentration under static condition in pipe. An empirical equation was proposed based on $T_{2}{ }^{*}$ and temperature to calculate the concentration in pipe.

Then the measurement of dynamic concentration of nanofluid under flow condition was carried out. The dynamic concentration distribution of the cross section was obtained with the $T_{2}{ }^{*}$ signals from different position of the cross section using the empirical equation. The dynamic concentration shows that the highest concentration appears near the wall, and then the concentration decrease along the radius to the centre of the pipe. The thermal conductivity of the nanofluid calculated with dynamic concentration is higher than that with uniform concentration. The reason of this phenomenon should be the boundary layer effect in the laminar flow, due to the flow velocity gradient. However, further analysis and mathematical model is still unknown. 
The present work proved that NMR can be a good method of measuring the concentration of nanofluid, and that the concentration gradient of nanofluid while flowing exists. The overall concentration measured from NMR matches well with the static concentration before experiment, and indicates the accuracy of the NMR measurement method.

The current method is only applied in ferrofluid, further work would be carried out trying to find the patterns of different nanofluids under NMR. And the theoretical analysis of the phenomenon and its mathematical model is also needed in the future.

\section{Acknowledgements}

This work is sponsored by EPSRC pump prime fund (2014-2015) at University of Nottingham.

\section{References}

1. Maxwell, J.C., A treatise on electricity and magnetism. Vol. 1. 1881: Clarendon press.

2. Chol, S., Enhancing thermal conductivity of fluids with nanoparticles. ASME-Publications-Fed, 1995. 231: p. 99-106.

3. Wong, K.V. and O. De Leon, Applications of nanofluids: current and future. Advances in Mechanical Engineering, 2010. 2010.

4. Kim, S., et al., Surface wettability change during pool boiling of nanofluids and its effect on critical heat flux. International Journal of Heat and Mass Transfer, 2007. 50(19): p. 4105-4116.

5. Chopkar, M., P.K. Das, and I. Manna, Synthesis and characterization of nanofluid for advanced heat transfer applications. Scripta Materialia, 2006. 55(6): p. 549-552.

6. Singh, D., J. Toutbort, and G. Chen, Heavy vehicle systems optimization merit review and peer evaluation. Annual Report, Argonne National Laboratory, 2006. 23: p. 405-411.

7. Kao, M., et al., Copper-oxide brake nanofluid manufactured using arc-submerged nanoparticle synthesis system. Journal of Alloys and Compounds, 2007. 434: p. 672-674.

8. Kleinstreuer, C., J. Li, and J. Koo, Microfluidics of nano-drug delivery. International Journal of Heat and Mass Transfer, 2008. 51(23): p. 5590-5597.

9. Bica, D., et al., Sterically stabilized water based magnetic fluids: Synthesis, structure and properties. Journal of Magnetism and Magnetic Materials, 2007. 311(1): p. 17-21.

10. Wasan, D.T. and A.D. Nikolov, Spreading of nanofluids on solids. Nature, 2003. 423(6936): $p$. 156-159.

11. Borbath, T., et al., Leakage-free rotating seal systems with magnetic nanofluids and magnetic composite fluids designed for various applications. International Journal of Fluid Machinery and Systems, 2011. 4(1): p. 67-75.

12. Mondragón, R., et al., Experimental characterization and modeling of thermophysical properties of nanofluids at high temperature conditions for heat transfer applications. Powder 
Technology, 2013. 249: p. 516-529.

13. Alsaady, M., et al., Thermo-physical properties and thermo-magnetic convection of ferrofluid. Applied Thermal Engineering,2015. 88: p.14-21.

14. Zeinali Heris, S., S.G. Etemad, and M. Nasr Esfahany, Experimental investigation of oxide nanofluids laminar flow convective heat transfer. International Communications in Heat and Mass Transfer, 2006. 33(4): p. 529-535.

15. Zhou, D., Heat transfer enhancement of copper nanofluid with acoustic cavitation. International Journal of Heat and Mass Transfer, 2004. 47(14): p. 3109-3117.

16. Lee, J.-H., et al., Effective viscosities and thermal conductivities of aqueous nanofluids containing low volume concentrations of Al2O3 nanoparticles. International Journal of Heat and Mass Transfer, 2008. 51(11): p. 2651-2656.

17. Quemada, D. and C. Berli, Energy of interaction in colloids and its implications in rheological modeling. Advances in colloid and interface science, 2002. 98(1): p. 51-85.

18. Evans, W., J. Fish, and P. Keblinski, Role of Brownian motion hydrodynamics on nanofluid thermal conductivity. Applied Physics Letters, 2006. 88(9): p. 093116.

19. Bryant, D.J., et al., Measurement of Flow with NMR Imaging Using a Gradient Pulse and Phase Difference Technique. Journal of Computer Assisted Tomography, 1984. 8(4): p. 588-593.

20. Caprihan, A. and E. Fukushima, Flow measurements by NMR. Physics Reports, 1990. 198(4): p. 195-235.

21. Callaghan, P.T., Principles of nuclear magnetic resonance microscopy. Vol. 3. 1991: Clarendon Press Oxford.

22. Runge, V.M., et al., Work in progress: potential oral and intravenous paramagnetic NMR contrast agents. Radiology, 1983. 147(3): p. 789-791.

23. Babes, L., et al., Synthesis of iron oxide nanoparticles used as MRI contrast agents: a parametric study. Journal of Colloid and Interface Science, 1999. 212(2): p. 474-482.

24. Bulte, J.W. and D.L. Kraitchman, Iron oxide MR contrast agents for molecular and cellular imaging. NMR in Biomedicine, 2004. 17(7): p. 484-499.

25. Parker, D.L., et al., Temperature distribution measurements in two - dimensional NMR imaging. Medical physics, 1983. 10(3): p. 321-325.

26. Rosen, B.R., et al., Perfusion imaging with NMR contrast agents. Magnetic Resonance in Medicine, 1990. 14(2): p. 249-265.

27. Kakaç S, Pramuanjaroenkij A. Single-phase and two-phase treatments of convective heat transfer enhancement with nanofluids-A state-of-the-art review[J]. International Journal of Thermal Sciences, 2016, 100: p.75-97.

28. Mahian O, Kianifar A, Kalogirou S A, et al. A review of the applications of nanofluids in solar energy[J]. International Journal of Heat and Mass Transfer, 2013, 57(2): p.582-594.

29. Mahian O, Kianifar A, Kleinstreuer C, et al. A review of entropy generation in nanofluid flow[J]. International Journal of Heat and Mass Transfer, 2013, 65: p.514-532.

30. Rashidi I, Mahian O, Lorenzini G, et al. Natural convection of Al 20 3/water nanofluid in a square cavity: effects of heterogeneous heating $[\mathrm{J}]$. International Journal of Heat and Mass Transfer, 2014, 74: p.391-402.

31. Mahian O, Kianifar A, Wongwises S. Dispersion of ZnO nanoparticles in a mixture of ethylene glycol-water, exploration of temperature-dependent density, and sensitivity analysis[J]. Journal of Cluster Science, 2013, 24(4): p.1103-1114. 
32. Bashirnezhad K, Bazri S, Safaei M R, et al. Viscosity of nanofluids: a review of recent experimental studies[J]. International Communications in Heat and Mass Transfer, 2016, 73: p.114-123.

33. Mahian O, Kianifar A, Heris S Z, et al. Natural convection of silica nanofluids in square and triangular enclosures: Theoretical and experimental study[J]. International Journal of Heat and Mass Transfer, 2016, 99: p.792-804.

34. Mahian O, Kianifar A, Sahin A Z, et al. Performance analysis of a minichannel-based solar collector using different nanofluids[J]. Energy Conversion and Management, 2014, 88: p.129138.35 .

35. J. Hong., S. Liu, Yuying Yan, Bionic inspired study of heat pipe from plant water migration, Energy Procedia, 110 (2017) 567-573. 